\title{
nformación versus usuarios Una ventana activa para reconocer los elementos del patrimonio
}

\section{Resumen}

La necesidad social para el análisis de los objetos culturales, a través de la clasificación, el orden y la consiguiente acumulación de información. Como se trata de sistematizar el coleccionismo público de objetos y la apuesta en los Museos. La restricción y el apropiamiento de los campos semánticos por parte de los especialistas para todo usuario que no fuera especializado. El concepto actual de patrimonio. Patrimonio Cultural. ¿Por qué un macrotesauro de Patrimonio?¿Qué supone este proyecto como propuesta integradora de distintas disciplinas? El Tesauro en la navegación de la información, hacia una sistematización de las bases de datos. La diversidad del Patrimonio. ¿Qué encontramos los profesionales de la conservación y la restauración en el Tesauro? Los macros de procesos y técnicas, la interrelación y la importancia de las relaciones asociativas.

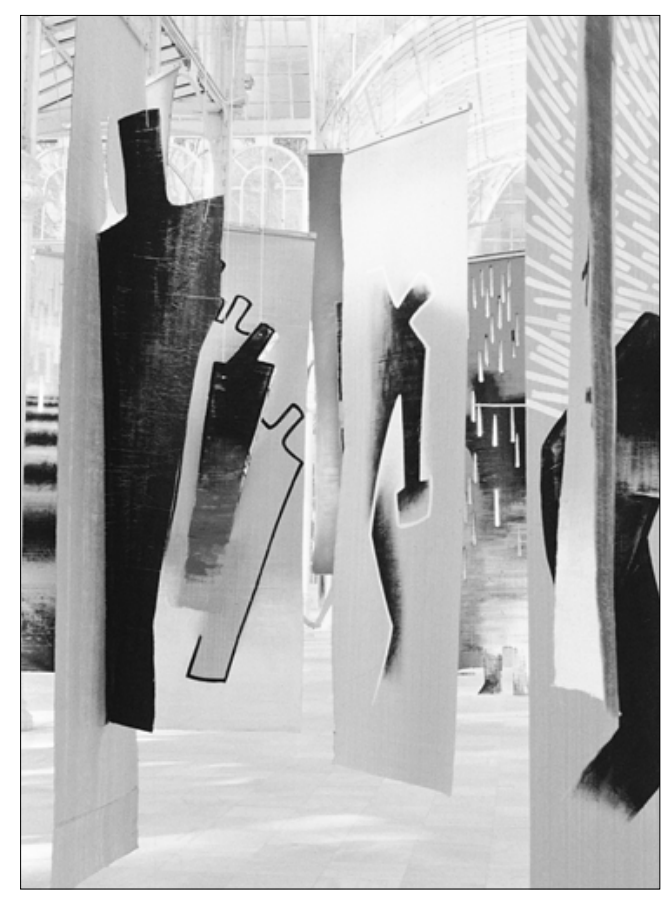

\section{Palabras clave}

Tesauros / Patrimonio Histórico / Andalucía / Usuarios / Información / Conservación-Restauración de Patrimonio / Museos / Multidisciplinas

Cuando surge la propuesta para trabajar en este proyecto, comenzó a entrelazarse muchas de las ideas cuestionadas, durante años de profesional con instituciones públicas o privadas donde realizaba mi trabajo.

Estas ideas tienen dos elementos comunes, el patrimonio cultural y su conservación, y el disfrute y la incorporación social de bienes, objetos o elementos que lo integran.

La dificultad de los profesionales de la conservaciónrestauración en el ámbito de actuación del Patrimonio viene definida de igual forma por la abundancia de referentes, por la multiplicidad de tipologías y métodos de creación, y finalmente por la dispersión geográfica en un territorio autonómico tan densamente prolífico en manifestaciones culturales a lo largo de la historia.

Creo que es interesante reflexionar primeramente sobre la necesidad que han tenido las distintas sociedades de analizar los objetos culturales, a través de la clasificación, el orden y en definitiva la acumulación de información

Desde el s. XIX decididamente, por no remontarnos a otras épocas de búsqueda del saber, se trata de sistematizar el coleccionismo de objetos sobre todo en el continente europeo con una apuesta rotunda por los museos públicos. Con ellos cada disciplina científica, técnica o ideológica, crea metodologías propias para el abordaje de esta cuestión, taxonomías irreductibles en cajones poco intercambiables, pero sobre todo han generado unos campos semánticos propios, restrictivos y que con el paso del 
Los profesionales de la conservación-restauración estamos delimitando un amplio espacio en donde por un lado se encuentran los objetos (productos del Patrimonio cultural), de otro las actuaciones y medidas a emprender y por ultimo el contexto, función o el ámbito donde se insertan. Todo ello produce los criterios necesarios para poder llevar a cabo su Tutela con efectividad.

tiempo han posibilitado un alejamiento por la especifidad de los términos y conceptos, de los ususarios no especialistas.

Más aún ahora, cuando el Patrimonio ha reivindicado para si todo lo que supone ser una actividad, un conjunto de bienes o una metodología de acercamiento a la cultura de un pueblo. Esto ha potenciado múltiples disciplinas, técnicos, científicos o críticos, y si ha sido necesario se han creado nuevos.

Hasta bien entrada la mitad de este siglo se ha mantenido el criterio decimonónico de preservar estas identidades que las disciplinas defienden. Ahora, de alguna manera, existe esa actitud continuista aunque parece que el concepto cambia, pensemos que han querido la exclusiva para relegar en un desván el conocimiento y la posibilidad de compartirlo y "usarlo" de manera extensiva.

Los objetos y las actividades, a mi entender, son deudoras de su entorno, de su valor o posición, de su función y para ello es necesario tratarlas con esa complejidad que exige su condición.

Es claro si observamos nuestra Ley del Patrimonio Andaluz del año 9l, en ella aparece como novedad la superación de lo histórico-artístico, incluso de lo monumental o arqueológico. Introduce elementos muy novedosos en lo antropológico, medio ambiente, patrimonio industrial, lugares, sitios de reserva o conjuntos, patrimonio y empleo, desarrollo o turismo.

También el propio concepto actual de Patrimonio Cultural es prueba de ello, "cultura es el conjunto de conocimientos y de valores que no es objeto de ninguna enseñanza específica y que sin embargo, todos los miembros de una comunidad conocen" (UNESCO) un patrimonio en la diversidad, en la simultaneidad de estrategias, en experiencias de acercamiento multidisciplinar y en un ancho de banda máximo para el uso de cada sociedad.

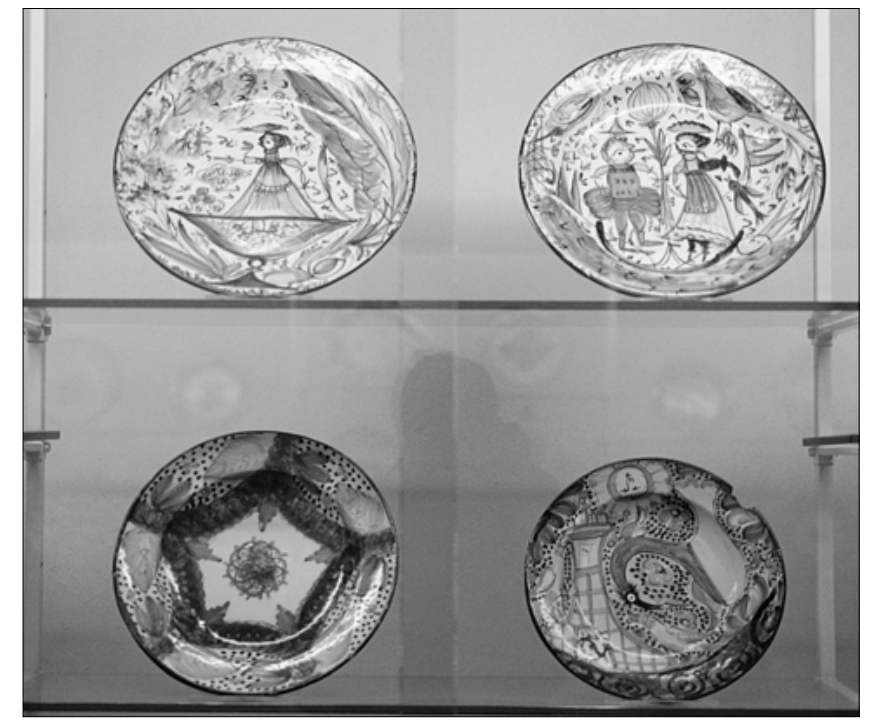

Por ello la creación de un macrotesauro del Patrimonio, trata en el proceso de discusión inicial por parte de todo el grupo de trabajo encargado de su redacción (I 3 personas)', de poner en relación esas disciplinas y los contenidos (grupos de ideas) que generan.

Es bien conocida la tradición de Tesauros específicos, de especialides, técnicas, disciplinas, objetos, actividades etc... pero ante esta consideración, el proyecto se definirá "como la creación de una norma que facilite las entradas y salidas de datos, en este caso de objetos, actividades, técnicas, procedimientos, agentes, estructuras socio-político-económicas, materiales, etc. que tienen que ver con el Patrimonio Cultural de los pueblos: Por ello creemos que este Patrimonio no es deudor, por tanto, de ninguna disciplina en exclusiva."

En el comienzo tenemos posiciones contrarias, que defiende apropiaciones reales en la práctica pero tozudas desde algunos sectores que entienden el conjunto de las disciplinas sólo como elementos de ase- 

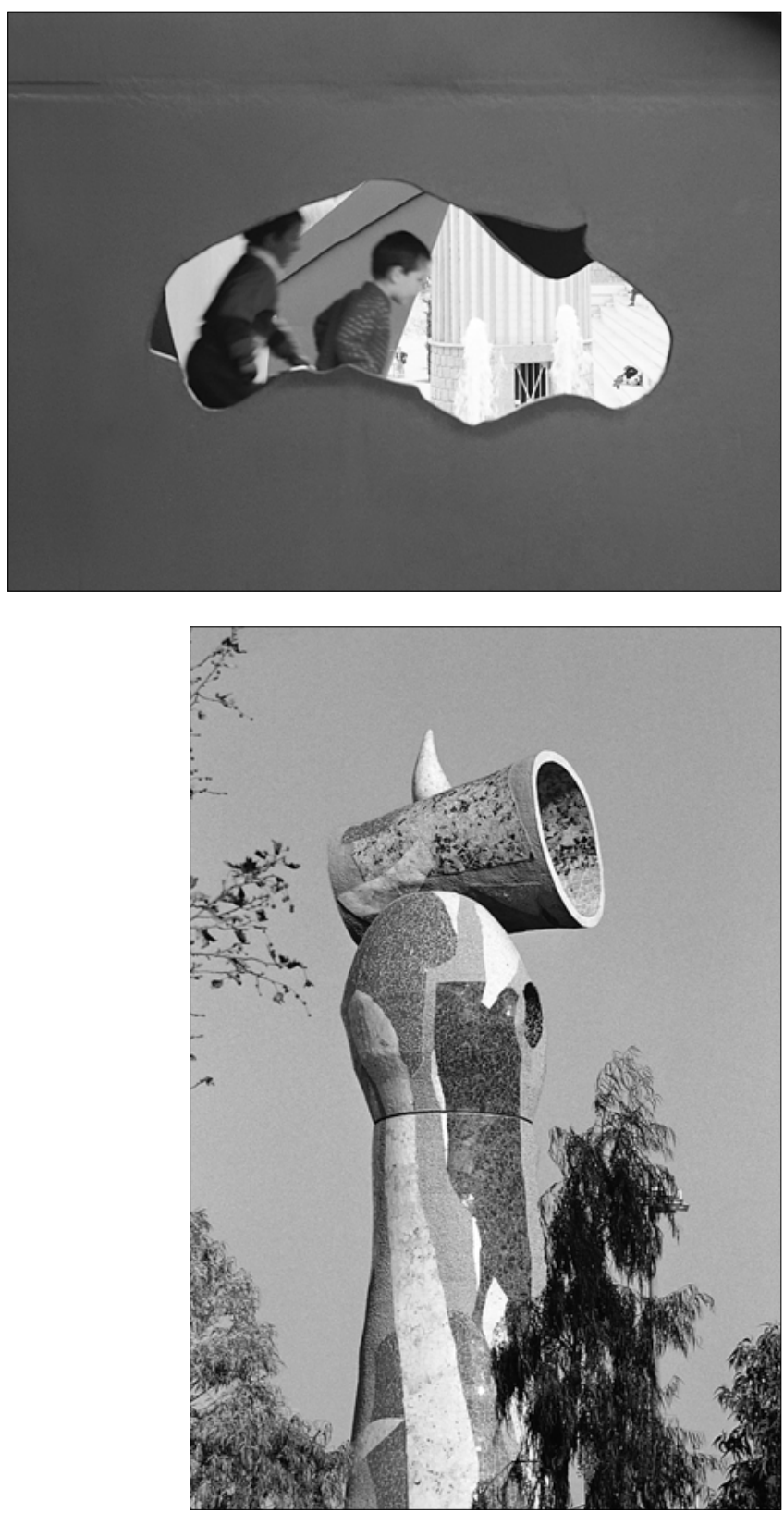

soría, consultivos y no fundamentales para una lectura completa. Que entienden lo patrimonial como un tesoro y sólo con objetos materiales producto de lo Histórico-artístico, volvemos a los conceptos encorsetados.

La creación de este proyecto, es por ello, el intento de una apuesta integradora una necesidad de abrir una ventana que oferte el reconocimiento de los usuarios hacia la presencia amplísima de los elementos que integran el Patrimonio Cultural.

La colisión en principio con el resto de tesauros o con otros programas de indización y clasificación empleados para otras instituciones ${ }^{2}$, nos hace adoptar un criterio común desarrollado en estos tres años de trabajo y que sólo será entendido desde la generosidad de los profesionales, formulando la utilización de conceptos y términos dentro de un territorio común ${ }^{3}$.
En principio se trabajará a partir de la norma ISO2788-1986(E) de "Directrices para el establecimiento y desarrollo de Tesauros monolingües" aunque pronto se despejaron dudas sobre el funcionamiento ya que el análisis de las primeras conclusiones y de los tesauros iniciales de referencia, nos muestran la aparición de lagunas; por ello se realizan convenciones y estrategias durante todo el proceso que ha generado no sólo un instrumento documental sino un banco de pruebas.

EI TPHA será concebido para cubrir la actividad indizadora-descriptiva y análitica en fase de entrada y salida de registros-que afecta a la información extraible de cualquier canal o soporte: textos escritos, audiovisuales e imágenes fijas, objetos muebles e inmuebles, actividades y acciones ${ }^{4}$.

En este aspecto el Tesauro es también integrador.

Pero un usuario, especializado o no, catalogador o investigador, tiene que tener la posibilidad de un referente que le permita navegar y realizar búsquedas en viajes de ida y vuelta.

Debe por tanto este TPHA (del que sólo se dispone de la Version 0 ) posibilitar una traducción del proceso final que el usuario demande. La excusa de la cantidad excesiva de información que genera el P. H. no debe ser un lastre ni razón suficiente para intentar hacerlo más fácil o crear sistemas que abran nuevas vías.

Muchas opiniones demandan en este sentido, la sistematización de manera integradora de las bases de datos del Patrimonio. Esta idea ya fué recogida en el primer Plan General de Bienes Culturales en 1989 y que al IAPH encomendaba en su Centro de Documentación del PH la normalización y sistematización, para que como un objetivo final prestara información a los diversos agentes que intervienen en la tutela del Patrimonio.

Bajo el concepto de Tutela, que recoge la investigación, conservación, intervención y difusión; entenderemos las estrategias de la sistematización de la información y su uso (su transferencia) como la mejor protección y conservación de nuestro Patrimonio.

La definición, la catalogación y la relación conceptual libera a los productos del patrimonio de la ignorancia y con ello de su pérdida irreparable.

Es la tutela lo que va a unir, como elemento común, a todos los integrantes del grupo de trabajo.

Son estas zonas comunes las que hacen patente el enfoque multidisciplinar para abarcar el Patrimonio lo que nos llelva a búsquedas lentas y esforzadas de convenciones y normas. Con el convencimiento de economizar términos y conceptos para no multiplicar herramientas de trabajo para documentalistas, profesionales y usuarios. 
Los elementos del Patrimonio participan de mucha información en sí mismos pero sobre todo en relación con los otros. Nuestro trabajo no es ajeno a la diversidad y es ésta la que nos ofrece más claro el concepto de Patrimonio Cultural.

\section{La conservación y restauración en el TPHA}

Este área de contenidos estará como el resto de disciplinas presente en el facetado disperso por la macroestructura. No se trata por tanto de un listado cerrado de términos sino fortalecer la estructura con una intima vinculación a las prouestas de otros profesionales 5 .

La ausencia de experiencias anteriores trata de integrar desde un primer momento los dos amplios conceptos: estrategias procedimentales e ideológicas. Los profesionales de la conservación-restauración estamos delimitando un amplio espacio en donde por un lado se encuentran los objetos (productos del Patrimonio cultural), de otro las actuaciones y medidas a emprender y por ultimo el contexto, función o el ámbito donde se insertan. Todo ello produce los criterios necesarios para poder llevar a cabo su Tutela con efectividad.

Por otro lado ha sido muy importante la participación en las técnicas y procedimientos de la creación, de la producción de estos objetos, de su deterioro, los materiales e instrumentos necesarios, los agentes que lo realizan, las actividades que producen, los estilos... es decir, participa de toda la estructura.

En un principio se plantean dos referencias importantes como son la sintonía con el proceso de normalización que se realiza en el Centro de Intervención del IAPH, junto a la Base de datos de Bienes Muebles del Centro de documentación ya recogidos en el Avance de Tesauro de 1994 con los que se colabora desde un primer momento ${ }^{6}$.

Como antes mencionábamos la conservación-restauración se encuentra diseminada en varias facetas del tesauro. En la Macrocategoría de 1000000 Acontecimientos. Actividades. Procesos. Técnicas, podemos citar: I 300000 Proceso

Alude a los cambios que experimentan en lo material y el medio donde se encuentra, considerado como intransitivo.

1310000 Indicadores de alteración

1320000 Proceso biológico

1340000 Proceso físico

I 360000 Proceso quimico etc... | 400000 Técnica

Las técnicas que si bien siempre se han entendido tradicionalmente como "aquellas que designan un conjunto de conocimientos y recursos que pueden servir para la ciencia o el arte, investigación o creación "(Diccionario UNESCO Ciencias sociales 1947), han sido consideradas dentro de la gramática de ca- sos (el modo) los procedimientos y las formas específicas que permiten una extensa acción sobre el medio. Tienen una funcionalidad primaria, con marcado carácter transitivo.

14 10000 Técnica de análisis de materiales

1430000 Técnica de conservación. Técnica de restauración

1480000 Tecnica de investigación I 490000 Técnica de limpieza etc. . .

Se ha tratado de vincular el estudio, análisis e investigación del estado de conservación con las propuesta de tratamientos definiendo:

Técnicas de conservación: Se refiere a aquellas técnicas, análisis y procedimientos aplicados a objetos
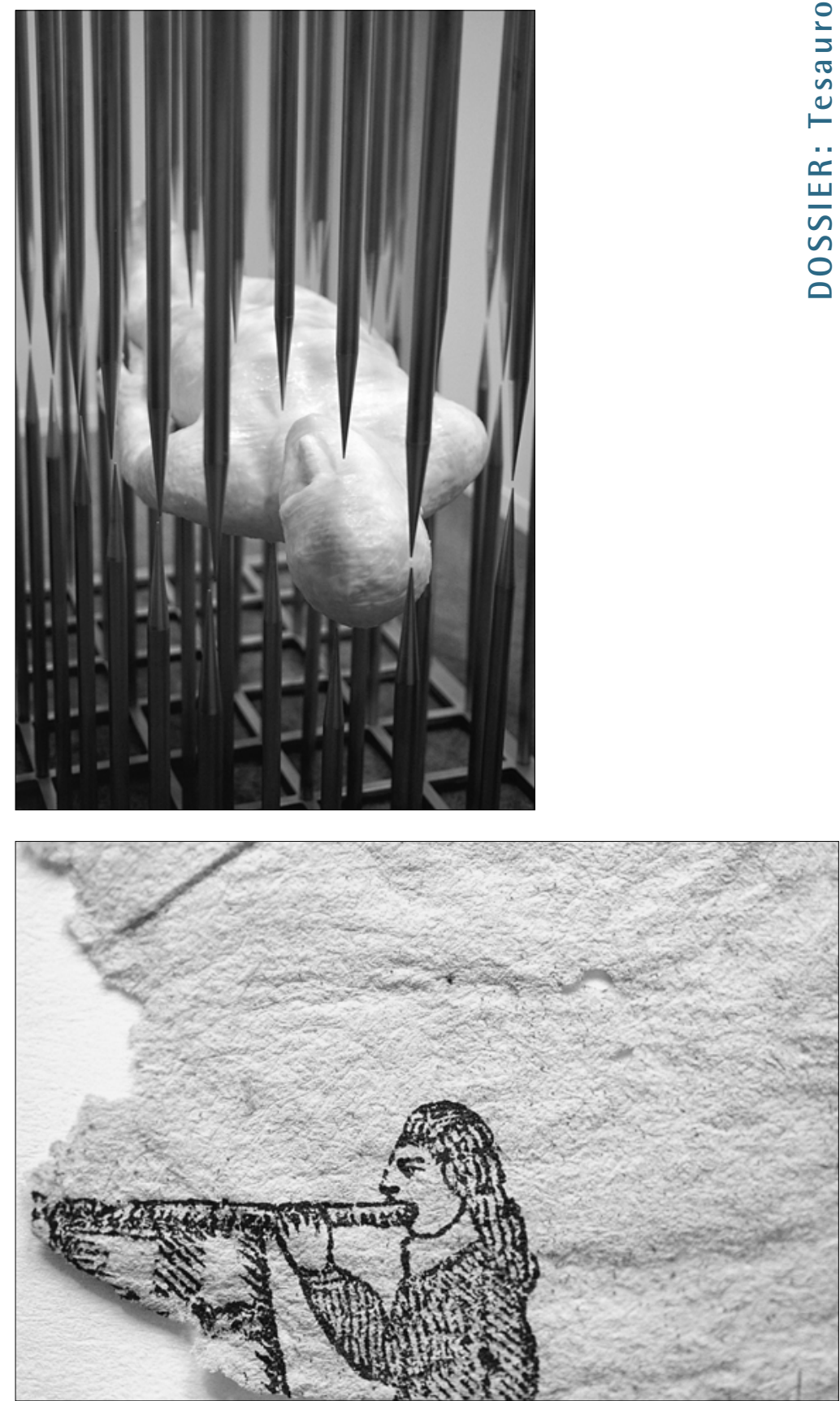


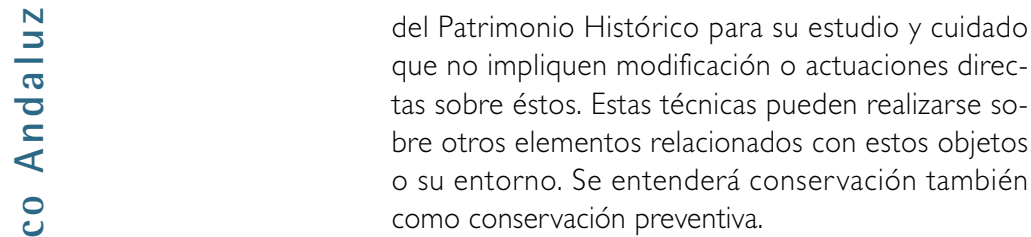

Técnicas de restauración: Toda acción o proceso directo sobre los objetos o materiales que supongan modificación o cambio en su estado de conservación. Cuando empleemos este descriptor equivaldrá a "conservación-restauración" para objetos. También equivaldrá a "rehabilitación arquitectónica". Combínese con los distintos macros de objetos, materiales, técnicas, etc.

I 4E0000 Técnica de representación gráfica I4E2000 Registro de imágenes I 4E3000 Técnica de dibujo
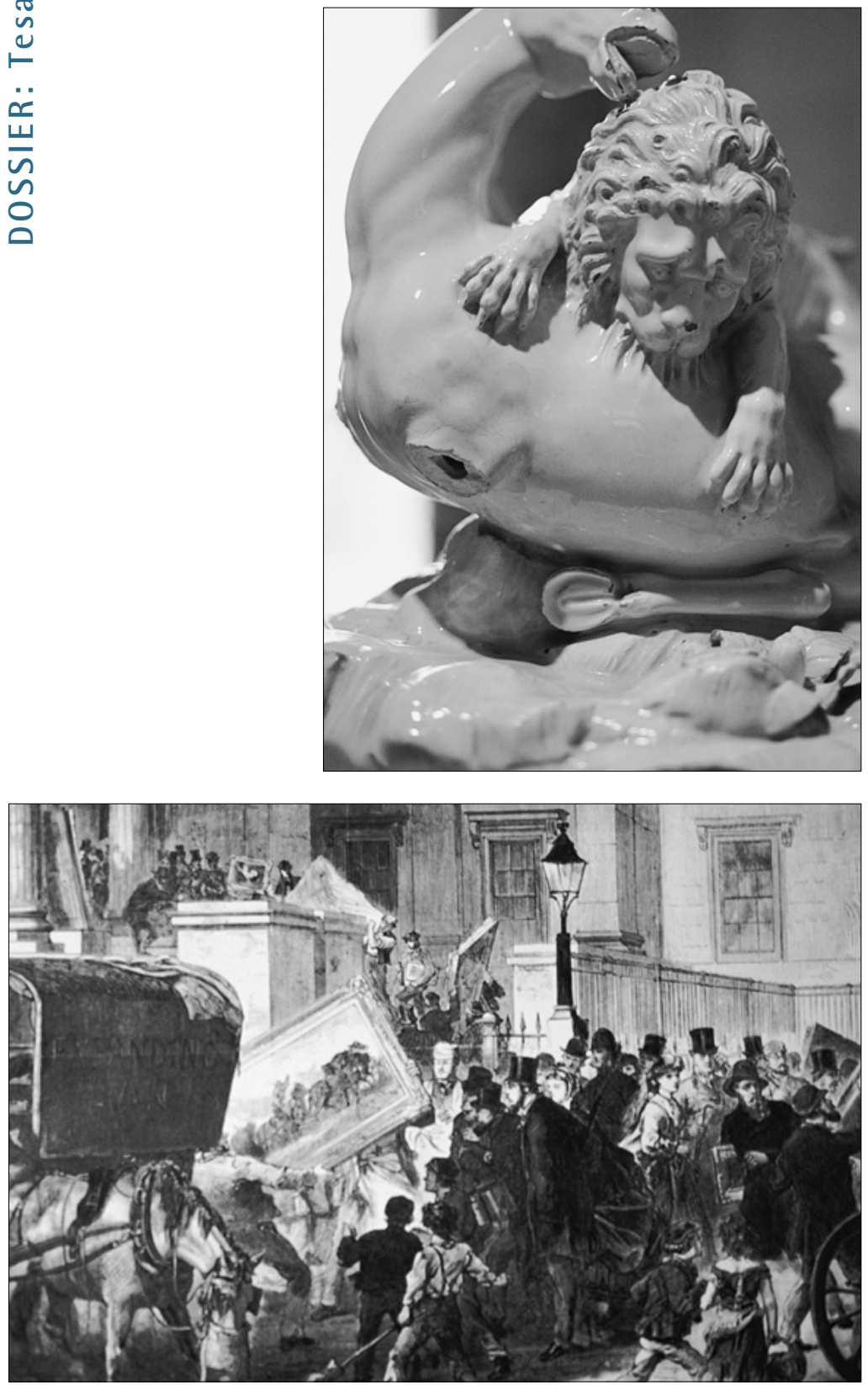

| 4E4000 Técnica de estampación. Tecnica de impresión

| 4E5000 Técnica Pictórica

I4G0000 Técnica de tratamiento de superficies etc...

Tratamos de especificar y diferenciar los propios procedimientos de creación con las técnicas que participan para posteriormente vincularlo a los objetos y a los materiales e instrumentos ${ }^{7}$.

Finalmente en esta breve descripción señalar la importancia de esta disciplina respecto de las colecciones públicas o privadas. Las necesidades y los planteamientos para su Musealización y las técnicas Museográficas para la exhibición de los objetos ${ }^{8}$.

No sólo se ha revisado por el grupo la dificultad en estas instituciones públicas del PH para la catalogación, puesto que en muchos casos los mismos objetos se categorizan, o se enmarcan tipológicamente de manera distinta por los diferentes catalogadores, sino que se plantea el objeto museable como documento 9 y como material a conservar sujeto a una transmisión de contenidos para el usuario.

Para nosotros ha sido muy importante tanto el continente Museo como el contenido, las colecciones que alberga, con la introducción de elementos en relación con el último planteamiento, sus necesidades museográficas y la relación con los usuarios.

Algunas referencias en el TPHA :

Museos 71124B3

Museología A 400000

Museografía A 400000

Programas museográficos A961000

Técnica museográfica 1400000

Edificios de exposiciones

Técnicas de exposición 1421000

Vitrinas 7291100

Instalaciones de Climatización 71 | 4300

Instalaciones de Seguridad 7| 14600

Técnica de conservación. Técnica de restauración 1430000

etc...

En este Tesauro la apuesta continua con las búsquedas cruzadas, la postcoordinación frente a la precoordinación y tratar de llegar a significados simples conectados por las interrelaciones de los TR (términos relacionados).

Las 15300 entradas aproximadamente del TPHA (revisados una a una por todo el equipo) son una reducción de algunos millares más que se van encadenando, pero tanto en este apartado como en otros se trata de crear un árbol de ramas consistentes renovables. El usuario no encontrará un viejo olmo de ramas enciclopédicas.

La diversidad de objetos, de elementos materiales e inmateriales, de procedimientos, de técnicas empleadas, de funciones y usos, de quienes la ejecutan, de las necesidades de su conservación o de las propias 
limitaciones por su materialidad o naturaleza, obligó a un feed-back continuo sobre una compleja macroestructura (la gran aportación de este TPH).

Nos permitió viajar desde nuestra disciplinas de manera horizontal y que posibilitara al usuario, como si de una consola de videojuegos se tratara de viajar en todas las direcciones y de incorporar nuevos términos candidatos alimentando el sistema (aunque todavía no se encuentra realizada la Version I en CDrom imprescindible).

Este trabajo en definitiva quiere ser una apuesta integradora frente a otros proyectos unívocos, la dificul- tad mayor se establece cuando ya diseñado un instrumento para un conjunto de funciones y aplicaciones ha de ser explicado, necesita un rodaje de aprendizaje con experimentación y sobre todo adaptándose a las circunstancias y cambios que se soliciten. Es la parte más árida del recorrido del proyecto.

Por ello el trabajo sólo ha comenzado, el saber si ocupa lugar y sobre todo tiempo. Por ello la retroalimentación del TPHA tiene que ser prograsiva en sintonía con la sistematización de las distintas bases de datos del Patrimonio del Centro de Documentación del IAPH, de las entidades e instituciones y los profesionales relacionados con éste.

\section{Fotografías:}

J. C. Roldán

\section{Notas}

I. Este grupo de profesionales de las disciplinas mas representativas en el Patrimonio Histórico, no sólo tiene el trabajo encomendado de compilar, debatir la inserción de los descriptores, sino que crea junto al director del proyecto un sistema jerárquico, nuevo y adaptado a un ámbito, el Patrimonio Cultural con una vocación integradora, sin ningún precedente documental.

2. Aunque creemos que son importantes las propuestas específcas que se vinculan a corpus, marcos de estudio: caso del DOCOMOMO surgido en 1988 desde la escuela de arquitectura de Eindhoven o el proyecto para la informatización de repertorios documentales y bases de datos en los museos ODISEUS. Por ello, no sólo entenderemos este proyecto de Tesauro como una investigación que potencie la interpretación cultural del Patrimonio sino como un intrumento de homogeneización terminológica.

3. Las disciplinas mas relacionadas en la elaboración de este TPH serán : Artes, Antropología, Archivística, Biblioteconomía, Documentación, Arqueología, Arquitectura, Geología, Física, Química, Historia, Museología, Conservación-restauración y el Derecho Patrimonialista entre otras.

4. Antonio García Gutiérrez : Principios del lenguaje epistemigráfico: la representación del conocimiento sobre Patrimonio Histórico Andaluz, pag. 50 capítulo IV. Cuadernos Técnicos Junta de Andalucía. 1988.

Vease del mismo autor: Procedimientos de análisis documental automático. Estudio de Caso. Cuadernos Técnicos Junta de Andalucía 1996.
5. Igualmente los defensores de los Tesauros temáticos por disciplinas reivindicaban una autoría y especifidad de términos, que fue ampliamente rebatida en los primeros meses de trabajo por la concurrencia y las polisemias que detectábamos.

6. Además de una extensa bibliografía temática consultada y utilizada pag 39 TPHA Versión 0. 1998

7. Referencias en Conservación-restauración en el Tesauro del Patrimonio Histórico Andaluz, 1998. Antonio Martín Pradas. sp.

8. En este área se ha realizado un trabajo conjunto con Manuel Ramos Lizana conservador de Museos y arqueólogo integrante del grupo de trabajo.

9. Documento como cualquier conocimiento materializado sobre un soporte y que pueda ser transmitidos. López Yepes. El tesauro pionero en el Mundo de los museos que recoge la experiencia en Museos americanos fué el Chenhall en 1978 Nomenclature for Museums Cataloging. 